\title{
INSPEKSI KESEHATAN LINGKUNGAN SEKOLAH DASAR DI KABUPATEN BANYUWANGI
}

\author{
Nur Risca Azizah ${ }^{1}$, Septa Indra Puspikawati ${ }^{2}$, Merrisa Ayu Oktanova ${ }^{3}$ \\ ${ }^{1}$ Program Studi S1 Kesehatan Masyarakat, PSDKU Universitas Airlangga di Banyuwangi \\ ${ }^{2}$ Departemen Gizi Kesehatan, Program Studi S1 Kesehatan Masyarakat, \\ PSDKU UNAIR di Banyuwangi \\ ${ }^{3}$ Puskesmas Mojopanggung, Banyuwangi \\ nur.risca.azizah-2014@fkm.unair.ac.id
}

\begin{abstract}
Bad school's environmental condition are risk of causing illness, health environment school inspection are required to keep school environment healtier and bring up pupil's living behavior. This study aimed to describe the condition of primary schools sanitation at working area of Mojopanggung Health Center Banyuwangi. This research method used observational descriptive with cross sectional approach. Sampling in this study used total sampling as 22 school respondents. This research started from Januari until February 2018. Variables of this reseacrh are school environment, sanitation facility, school building, student personal hygine, and other variable. Variables were measured using health inspection instrument of school environment by East Java Provincial Health Office. Data were analyzed descriptively by showing frequency distribution of each variable. This research result's showed that school environment variables are 100\% going well, there are 2 schools $(9,1 \%)$ have a poor school facilities because of their geographical location are higher than other school areas. There is 1 school $(4,6 \%)$ that has poor buildings because the classroom is not tidy and dirty. there are student in 3 schools $(13,6 \%)$ whose has a poor personal hygine, many student have a long and dirty nails.
\end{abstract}

Keywords: inspections, health environment school, school sanitation

\begin{abstract}
ABSTRAK
Kondisi lingkungan sekolah yang buruk berisiko menimbulkan penyakit, untuk itu inspeksi kesehatan lingkungan sekolah diperlukan guna menjaga lingkungan sekolah agar tetap sehat serta terwujud perilaku hidup bersih dan sehat bagi siswa. Penelitian ini bertujuan untuk mendeskripsikan gambaran sanitasi sekolah dasar yang berada di wilayah kerja Puskesmas Mojopanggung Banyuwangi. Metode penelitian ini adalah desktiptif observasional dengan rancangan cross sectional. Penelitian ini menggunakan total sampling yaitu 22 sekolah dasar. Penelitian dilakukan pada bulan Januari-Februari 2018. Variabel penelitian terdiri dari variabel lingkungan, fasilitas sanitasi, bangunan atau gedung, kebersihan perorangan dan lain-lain. Variabel tersebut diukur dengan instrumen inspeksi kesehatan lingkungan sekolah yang dibuat oleh Dinas Kesehatan Provinsi Jawa Timur. Data dianalisis secara deskriptif dengan menampilkan distribusi frekuensi dari masing-masing variabel. Hasil penelitian menunjukkan bahwa semua sekolah (100\%) telah memenuhi variabel lingkungan dengan baik, sebanyak 2 sekolah $(9,1 \%)$ memiliki fasilitas sekolah kurang baik karena pengaruh letak geografis wilayahnya yang lebih tinggi dari area sekolah lain. Terdapat 1 sekolah $(4,6 \%)$ yang memiliki bangunan kurang baik karena ruangan kelas tidak rapi dan kotor. Masih ada murid di 3 sekolah $(13,6 \%)$ yang kebersihan perorangannya kurang baik, masih banyak siswa yang memiliki kuku yang panjang dan kotor.
\end{abstract}

Kata Kunci : Inspeksi, kesehatan lingkungan sekolah, sanitasi sekolah 


\section{PENDAHULUAN}

Setiap anak Indonesia memiliki hak untuk mendapatkan lingkungan sekolah sehat, aman dan nyaman seperti yang diamanatkan oleh Undang-Undang Kesehatan Nomor 36 Tahun 2009 tentang Kesehatan. Pasal 79 menjelaskan bahwa kesehatan sekolah diselenggarakan agar kemampuan hidup peserta didik dapat meningkat dalam lingkungan yang sehat, sehingga mereka dapat belajar secara nyaman dan bertumbuh kembang secara optimal untuk menjadi sumber daya manusia yang berkualitas (UU RI, 2009). Pada tingkat global, sanitasi sekolah merupakan salah satu prioritas pembangunan sesuai dengan tujuan $4 \mathrm{a}$ dalam SDGs (Sustainable Development Goals), sedangkan di Indonesia, pemerintah telah berkomitmen untuk mentargetkan pelaksanaan sanitasi sekolah dalam Rencana Pembangunan Jangka Menengah Nasional (RJPMN) dalam kurun waktu 2015-2019. Sekolah merupakan tempat yang penting dan perlu perhatian khusus karena sekolah merupakan tempat belajar siswa selain di rumah. Sebagian besar siswa dapat menghabiskan waktu berjam-jam di sekolah. Padahal, lingkungan fisik dan kebersihan fasilitas sekolah dapat secara signifikan mempengaruhi kesehatan dan kesejahteraan siswa. Penyakit dapat dengan cepat menyebar di ruang kelas yang sempit dan minim ventilasi, tidak tersedianya sabun dan fasilitas cuci tangan serta rusak atau tidak adanya toilet yang memenuhi persyaratan di sekolah (UNICEF Indonesia, 2012).

Tersedianya sanitasi sekolah yang memadai akan berdampak besar terhadap beberapa indikator utama pembangunan sektor kesehatan, pendidikan, ekonomi, kesetaraan gender serta air dan sanitasi. Pada sektor kesehatan, kegiatan cuci tangan merupakan sebuah hal yang sederhana, namun apabila kegiatan cuci tangan dapat terlaksana dengan baik dan benar sesuai syarat kesehatan yaitu dengan menggunakan sabun dan air mengalir, dapat mengurangi risiko terserang penyakit diare hingga 47\% (Freeman, dkk., 2014). Dari sektor kesetaraan gender, penelitian global yang dilakukan oleh UNESCO menyatakan bahwa akibat fasilitas sanitasi yang tidak layak di sekolah membuat 1 dari 5 anak perempuan tidak melanjutkan sekolah ke jenjang pendidikan menengah (UNESCO, 2010).
Penelitian yang sama menyatakan bahwa akibat sanitasi sekolah yang tidak layak membuat 1 dari 6 orang peserta didik perempuan yang sedang menstruasi terpaksa membolos (Burnet Institute, 2015).

Kondisi sanitasi sekolah dasar di Indonesia lebih buruk dibandingkan dengan jenjang sekolah lainnya, dimana indeks sanitasi sekolah dasar hanya sebesar 53,75\% (Pusat Data dan Statistik Pendidikan dan Kebudayaan, 2017). Peneltian Tambuwun et al. (2015) menyatakan bahwa, terdapat hubungan yang bermakna antara sanitasi lingkungan dengan kejadian diare pada anak usia sekolah di wilayah kerja puskesmas Bahu manado dengan odds rasio sebesar 10,769. Hal itu berarti, apabila kondisi sanitasi lingkungan buruk maka memiliki peluang diare sebesar 10,769 kali (Tambuwun et al., 2015). Kondisi berisiko timbulnya suatu penyakit dapat ditanggulangi dengan membuat fasilitas sanitasi yang mendukung.

UNICEF Indonesia menyebutkan bahwa sanitasi dan perilaku kebersihan yang buruk serta air minum yang tidak aman juga berkontribusi terhadap $88 \%$ kematian anak akibat diare di seluruh dunia. Mencuci tangan secara tepat dapat mengurangi resiko penyakit diare sebesar $47 \%$ dan infeksi pernapasan akut sebesar $30 \%$. Selain dapat menyebabkan penyakit diare, sanitasi yang tidak memadai, praktek kebersihan yang buruk, serta air yang terkontaminasi dapat menyebabkan penyakit lain yang meliputi disentri, kolera, tipus, hepatitis, leptospirosis, malaria, demam berdarah, kudis, penyakit pernapasan kronis dan infeksi parasit usus (Freeman, 2006). Sanitasi dasar merupakan faktor yang dominan terhadap kesehatan siswa sekolah dasar. Untuk itu, pengawasan hingga monitoring dalam bentuk inspeksi sanitasi kesehatan lingkungan sekolah perlu dilakukan dengan baik dan rutin agar pihak puskesmas mengetahui efektifitas program yang telah diterapkan.

Puskesmas Mojopanggung telah melakukan kegiatan pengawasan terhadap Tempat-Tempat Umum (TTU) sebanyak 2 kali dalam satu tahun. Biasanya kegiatan pengawasan tersebut dilaksanakan pada awal tahun dan pertengahan tahun. Kunjungan pertama yang dilakukan bertujuan untuk 
inspeksi sanitasi atau melakukan penilaian kepada seluruh STTU yang ada seperti Sekolah, Hotel, dan Ponpes. Hasil total penilaian digunakan sebagai acuan dalam mengkategorikan memenuhi syarat atau tidaknya sebuah sekolah dengan standar penilaian yang ada. Setelah itu, hasil penilaian disampaikan kepada pihak sekolah. Bagi sekolah yang mendapat kategori tidak memenuhi syarat (TMS) akan mendapatkan sosialisasi KIE sesuai dengan variabel yang penilaiannya kurang. Kunjungan kedua (pertengahan tahun) bertujuan untuk memonitoring dan mengintervensi sekolah yang tidak memenuhi syarat untuk melihat penerapan hasil sosialisasi yang sudah diberikan oleh pihak puskesmas saat kunjungan pertama dilakukan. Dikarenakan penelitian ini dilakukan pada awal tahun dan bertepatan dengan pelaksanaan inspeksi sanitasi sekolah, maka penelitian ini bertujuan untuk mendeskripsikan gambaran pelaksanaan sanitasi sekolah dasar yang berada di wilayah kerja Puskesmas Mojopanggung Kabupaten Banyuwangi.

\section{METODE}

Penelitian ini merupakan penelitian deskriptif observasional, dengan menggunakan rancangan cross sectional. Populasi penelitian adalah seluruh sekolah dasar yang terdapat di wilayah kerja UPTD Puskesmas Mojopanggung di wilayah Kelurahan Giri, Mojopanggung, Jambesari, Grogol dan Penataban yang berjumlah 22 sekolah dasar yang diambil semua sebagai sampel (total sampling). Sedangkan untuk variabel kebersihan perorangan dilakukan secara accidental sampling dimana pengambilan sampel dilakukan pada responden yang kebetulan terdapat di lokasi penelitian (Notoatmojo, 2010). Sehingga peneliti mengambil responden yang pada saat observasi dilakukan.

Pengambilan data dilakukan dengan observasi dengan menggunakan instrumen terkait kondisi kesehatan lingkungan yang ada di masing-masing-masing sekolah dasar. Lembar instrumen yang digunakan merupakan form inspeksi kesehatan lingkungan sekolah yang berasal dari Dinas Kesehatan Provinsi Jawa Timur. Form ini digunakan oleh seluruh Puskesmas di Wilayah Provinsi Jawa Timur untuk menilai kesehatan lingkungan sekolah. Observasi dilakukan pada variabel lingkungan (terdiri dari halaman, tempat pengumpulan sampah, pembuangan air limbah), variabel fasilitas sanitasi (terdiri dari penyediaan air bersih, kamar mandi, jamban), variabel bangunan atau gedung (terdiri dari ruang kelas dan ruang guru), variabel kebersihan perorangan (terdiri dari kebersihan pakaian dan badan serta kebersihan kuku dan tangan) dan variabel lain-lain (terdiri dari kantin sekolah, penyediaan tempat cuci tangan dan kotak P3K). Pada masing-masing variabel tersebut akan dinilai dan dikategorikan menjadi baik dan buruk. Pengkategorian tersebut diperoleh dari penilaian masing-masing variabel dimana tiap sub variabel tersebut memiliki nilai tertinggi 5, nilai sedang 3 dan nilai rendah 2 . Kemudian seluruh nilai di total sehingga diperoleh kondisi sanitasi sekolah yang dikategorikan menjadi 3 kategori, yaitu memenuhi syarat (MS), keadaan sedang (S), dan keadaan tidak memenuhi syarat (TMS). Kategori sekolah yang memenuhi syarat memiliki total nilai sebanyak > $52-65$, keadaan sedang memiliki total nilai antara 39 52 , sedangkan sekolah yang tidak memenuhi syarat memiliki nilai dari hasil observasi $<39$. 
HASIL

Gambaran Lingkungan Sekolah

Tabel 1. Gambaran lingkungan sekolah

\begin{tabular}{|l|r|c|}
\hline \multirow{2}{*}{$\begin{array}{c}\text { Lingkungan } \\
\text { Sekolah }\end{array}$} & \multicolumn{2}{|c|}{ Jumlah } \\
\cline { 2 - 3 } & $\mathbf{n}$ & $\mathbf{\%}$ \\
\hline Baik & 22 & 100 \\
\hline Kurang Baik & 0 & 0 \\
\hline Total & 22 & 100 \\
\hline
\end{tabular}

Sumber: data primer

Hasil penelitian menunjukkan bahwa kondisi kesehatan lingkungan sekolah pada semua sekolah dasar (100\%) di wilayah kerja Puskesmas Mojopanggung sudah baik.

\section{Gambaran Fasilitas sekolah}

Tabel 2. Gambaran Fasilitas Sekolah

\begin{tabular}{|l|c|c|c|}
\hline \multirow{2}{*}{$\begin{array}{c}\text { Fasilitas } \\
\text { Sekolah }\end{array}$} & & \multicolumn{2}{c|}{ Jumlah } \\
\cline { 2 - 4 } & n & & \% \\
\hline Baik & 20 & & 90,9 \\
\hline Kurang Baik & 2 & & 9,1 \\
\hline Total & 22 & & 100 \\
\hline
\end{tabular}

Sumber: data primer

Berdasarkan hasil observasi terhadap fasilitas sanitasi sekolah yang meliputi air bersih, kamar mandi dan jamban didapatkan hasil

\section{Gambaran Bangunan Sekolah}

Tabel 3. Gambaran Bangunan Sekolah

\begin{tabular}{|l|c|c|}
\hline \multicolumn{1}{|c|}{ Bangunan } & \multicolumn{2}{c|}{ Jumlah } \\
\hline Sekolah & n & \% \\
\hline Baik & 21 & 95,4 \\
\hline Kurang Baik & 1 & 4,6 \\
\hline Total & 22 & 100 \\
\hline
\end{tabular}

Sumber: data primer

Penilaian pada variabel ini terdiri dari penilaian terhadap 2 ruangan, yaitu ruangan guru dan ruangan kelas siswa. Berdasarkan

hasil observasi yang telah dilakukan, sebanyak 21 bangunan sekolah atau sebesar 95,4\% telah memiliki ruangan kelas yang baik.

\section{Gambaran Kebersihan Perorangan}

Tabel 4. Gambaran Kebersihan Perorangan

\begin{tabular}{|l|c|c|}
\hline \multirow{2}{*}{$\begin{array}{c}\text { Kebersihan } \\
\text { Perorangan }\end{array}$} & \multicolumn{2}{|c|}{ Jumlah } \\
\cline { 2 - 3 } & n & \% \\
\hline Baik & 19 & 86,4 \\
\hline Kurang Baik & 3 & 13,6 \\
\hline Total & 22 & 100 \\
\hline
\end{tabular}

Sumber: data primer 
Berdasarkan hasil observasi terhadap sudah memenuh syarat.

kebersihan perorangan sebanyak $19(86,4 \%)$

Gambaran Lain-Lain

Tabel 5. Gambaran Lain-lain

\begin{tabular}{|l|c|c|}
\cline { 2 - 3 } \multicolumn{2}{c|}{ Lain-Lain } & \multicolumn{2}{c|}{ Jumlah } \\
\cline { 2 - 3 } & $\mathbf{n}$ & \% \\
\hline Baik & 18 & 81,8 \\
\hline Kurang Baik & 4 & 18,2 \\
\hline Total & 22 & 100 \\
\hline
\end{tabular}

Sumber: data primer

Berdasarkan hasil observasi yang telah dilakukan terhadap variabel lain-lain, kotak P2K dan pelaksanaan kantin sekolah didapatkan hasil bahwa sebanyak 18 sekolah sehat.

$(81,8 \%)$ sudah ,emcapai kategoru baik dala pelaksanaan penyediaan wastafel, persediaan

Gambaran Hasil Inspeksi Kesehatan Lingkungan Sekolah

Tabel 6. Gambaran Hasil Inspeksi Kesehatan Lingkungan Sekolah Dasar di wilayah kerja Puskesmas Mojopanggung Banyuwangi

\begin{tabular}{|c|l|c|c|c|}
\hline \multirow{2}{*}{ No } & \multicolumn{1}{|c|}{$\begin{array}{c}\text { Daftar Nama } \\
\text { Sekolah }\end{array}$} & \multicolumn{3}{c|}{$\begin{array}{c}\text { Hasil Inspeksi } \\
\text { Sekolah }\end{array}$} \\
\cline { 3 - 5 } & \multicolumn{1}{|c|}{ MS } & S & TMS \\
\hline 1 & Sekolah A & - & $\sqrt{ }$ & - \\
\hline 2 & Sekolah B & $\sqrt{ }$ & - & - \\
\hline 3 & Sekolah C & $\sqrt{ }$ & - & - \\
\hline 4 & Sekolah D & $\sqrt{ }$ & - & - \\
\hline 5 & Sekolah E & $\sqrt{ }$ & - & - \\
\hline 6 & Sekolah F & - & $\sqrt{ }$ & - \\
\hline 7 & Sekolah G & - & $\sqrt{ }$ & - \\
\hline 8. & Sekolah H & $\sqrt{ }$ & - & - \\
\hline 9. & Sekolah I & $\sqrt{ }$ & - & - \\
\hline 10. & Sekolah J & $\sqrt{ }$ & - & - \\
\hline 11 & Sekolah K & $\sqrt{ }$ & - & - \\
\hline 12 & Sekolah L & $\sqrt{ }$ & - & - \\
\hline 13 & Sekolah M & $\sqrt{ }$ & - & - \\
\hline 14 & Sekolah N & $\sqrt{ }$ & - & - \\
\hline 15 & Sekolah O & $\sqrt{ }$ & - & - \\
\hline 16 & Sekolah P & - & $\sqrt{ }$ & - \\
\hline 17 & Sekolah Q & $\sqrt{ }$ & - & - \\
\hline 18 & Sekolah R & & \\
\hline S & & & & - \\
\hline
\end{tabular}

Sumber: data primer 
Tabel 6. Gambaran Hasil Inspeksi Kesehatan Lingkungan Sekolah Dasar di wilayah kerja Puskesmas Mojopanggung Banyuwangi

\begin{tabular}{|c|l|c|c|c|}
\hline \multirow{2}{*}{ No } & \multicolumn{1}{|c|}{$\begin{array}{c}\text { Daftar Nama } \\
\text { Sekolah }\end{array}$} & \multicolumn{3}{c|}{$\begin{array}{c}\text { Hasil Inspeksi } \\
\text { Sekolah }\end{array}$} \\
\cline { 3 - 5 } & \multicolumn{1}{|c|}{$\begin{array}{c}\text { MS } \\
\text { Sekolah S }\end{array}$} & $\sqrt{ }$ & - & TMS \\
\hline 20 & Sekolah T & $\sqrt{ }$ & - & - \\
\hline 21 & Sekolah U & $\sqrt{ }$ & - & - \\
\hline 22 & Sekolah V & $\sqrt{ }$ & - & - \\
\hline
\end{tabular}

Keterangan : MS (Memenuhi Syarat), S (Keadaan Sedang / kurang memenuhi syarat).

Tabel diatas menunjukkan bahwa dari 22 sekolah dasar yang ada, terdapat $4(18,18 \%)$ sekolah dasar yang sedang atau kurang memehuni syarat.

\section{PEMBAHASAN}

\section{Gambaran Lingkungan Sekolah}

Berdasarkan hasil penelitian yang telah dilakukan terhadap variabel lingkungan sekolah, didapatkan hasil bahwa semua sekolah terlihat bersih, tidak ada sampah berserakan dan tidak ada genangan air. Sebanyak $95 \%$ Konstruksi saluran pembuangan air limbah di setiap sekolah sudah tertutup dan aliran lancar. Air limbah adalah air buangan dari aktivitas manusia yang dalam pemanfaatannya menggunakan air bersih, mengandung zat yang bersifat membahayakan makluk hidup dan biasanya muncul akibat perbuatan manusia seperti industrialisasi (Supriyanto, 2000).

Masing-masing sekolah masih memiliki tempat pengumpulan sampah yang kotor walaupun kondisi tempat sampah tertutup. Sebanyak 6 sekolah tidak membuang sampah ke TPS selama 1x24 jam. Sampah yang dibiarkan menumpuk akan berpotensi mencemari lingkungan sekitar karena bau dan air lindi yang dihasilkan dapat menurunkan kualitas udara, selain itu juga dapat menjadi tempat perindukan vector penyakit dan mengganggu estetika (Mukono, 2006).

Pada umumnya jenis sampah di tiap sekolah merupakan jenis sampah Rubbish. Sampah rubbish merupakan sampah yang mudah atau susah dibakar, contoh sampah yang mudah terbakar umumnya terdiri dari zat organiek seperti sampah dedaunan, kertas, plastik. Sedangkan sampah yang tidak mudah terbakar seperti kaleng merupakan jenis sampah anorganik (Mukono, 2006). Sampah yang mudah dibakar selanjutnya oleh pihak sekolah di buang ke lubang pembuangan sementara untuk kemudian di bakar. Banyak pihak sekolah melakukan pembakaran karena lokasi sekolah yang tidak terjangkau oleh pasukan kuning yang mengangkut sampah ke TPA. Mengubur atau membakar sampah diperbolehkan untuk dilakukan apabila sekolah tidak memiliki jangkauan terhadap TPA. Penguburan atau pembakaran sampah dilakukan setiap 3 hari sekali atau ketika sampah sudah sangat menumpuk (Kementerian Kesehatan Republik Indonesia, 2006) 
Nur, et al. Inspeksi Kesehatan Lingkungan Sekolah Dasar Wilayah Kerja Puskesmas Mojopanggung Banyuwangi

\section{Gambaran Lingkungan Fasilitas Sekolah}

Berdasarkan hasil penelitian yang telah dilakukan pada variabel fasilitas sekolah, didapatkan hasil bahwa sebagian besar sekolah memiliki air bersih sesuai syarat kesehatan serta kondisi kamar mandi dan jamban yang memenuhi syarat. Sumber air bersih yang digunakan oleh masing-masing sekolah berbeda- beda, hal itu tergantung dari letak wilayah geografisnya. Menurut peraturan menteri kesehatan No. 416 tahun 1990 air bersih merupakan air yang digunakan oleh manusia dalam memenuhi kebutuhan seharihari yang kualitasnya memenuhi syarat kesehatan dan dapat diminum apabila telah dimasak Jenis sarana air bersih ada beberapa macam yaitu PAM, sumur gali, sumur pompa tangan dangkal dan sumur pompa tangan dalam, tempat penampungan air hujan, penampungan mata air, dan perpipaan (Kementerian Kesehatan Republik Indonesia, 1990).

Sekolah yang berada di kelurahan atau desa Grogol, Jambesari, Penataban dan Giri menggunakan air perpipaan dari HIPPAM (Himpunan Penduduk Pemakai Air Minum) sedangkan untuk wilayah Boyolangu dan Mojopanggung menggunakan air dari PDAM sebagai sumber airnya. Hasil observasi menunjukkan bahwa 2 dari 22 total sekolah (9\%) yang masuk dalam kategori kurang baik menggunakan air sungai sebagai sumber air untuk memenuhi kebutuhan kamar mandi dan cuci tangan. Air sungai terlihat berwarna kecoklatan, keruh dan tidak berbau. Akses air bersih di Indonesia sebagian besar menggunakan air tawar yang berasal dari air sungai, sumur, waduk dan danau. Keberadaan sungai yang dekat dengan sekolah dan jauhnya sumber air PDAM / HIPPAM karena lokasi sekolah yang berada di geografis yang lebih tinggi dari area sekolah lain menjadi alasan bagi pihak sekolah dalam memanfaatkan air sungai tanpa melalui proses treatment atau pengolahan. Air sungai dialirkan langsung menuju kamar mandi sekolah. Meskipun air sungai terpenuhi syarat kuantitas dan kontinyuitasnya namun perlu diperhatikan juga kualitasnya. Kualitas air sungai bisa menurun akibat tercemarnya air sungai oleh aktivitas merugikan yang dilakukan oleh manusia, seperti pembuangan sampah, sisa pupuk atau pestisida pertanian, limbah industri dan rumah
JPH RECODE Oktober 2018; 2 (1) : 11-21 http://e-journal.unair.ac.id/JPHRECODE

tangga (Endang, 2014). Penelitian serupa dilakukan oleh Arisandi dan Ismail (2015) menyatakan bahwa terdapat 6 sekolah dari total 26 sekolah dasar di kecamatan Poli-Polia dan Ladong di Kolaka Timur memiliki kondisi sanitasi air bersih yang tidak memenuhi syarat.

Menurut Peraturan Menteri Kesehatan RI No. 1429 tahun 2006 (Kementerian Kesehatan Republik Indonesia, 2006), kamar mandi sekolah harus dalam keadaan bersih, tidak bau dan tersedia air dan sabun untuk mencuci tangan, namun untuk kebersihan kamar mandi di sekolah secara keseluruhan masih kotor dan bau (77\%). Selain itu, seluruh kamar mandi di masing-masing sekolah tidak tersedia sabun untuk mencuci tangan. Tiap-tiap kamar mandi pun sudah memiliki jamban leher angsa yang pembuangannya dialirkan ke tangka septic (91\%). Penyediaan sarana jamban merupakan salah satu usaha sanitasi yang penting dan seharusnya jamban dibuat terpisah antara siswa laki-laki dan perempuan. Di Indonesia, sekolah dasar yang memiliki jamban layak namun tidak dipisahkan sebanyak 31,40\% (Pusat Data dan Statistik Pendidikan dan Kebudayaan, 2017). Pembuangan tinja sembarangan atau tidak saniter dapat mencemari lingkungan terutama sumber air dan tanah. Kontaminasi tinja dapat menyebabkan penyakit seperti disentri, kolera, diare, thypus, schistosomiasis, penyakit yang ditularkan oleh cacing lainnya (gelang, kremi, tambang dan pita), dan penyakit lainnya.

Kebersihan kamar mandi harus dijaga, untuk itu selain upaya kebersihan yang dilakukan harus ada slogan kesehatan dan kebersihan atau promosi hygine dan sanitasi sekolah yang rutin agar meningkatkan pengetahuan siswa. Pengurasan bak mandi juga perlu dilakukan minimal 1 kali dalam seminggu untuk menghindari berkembangbiaknya vector penyebab penyakit seperti nyamuk Aedes Aegypti.

\section{Gambaran Bangunan Sekolah}

Berdasarkan hasil penelitian yang telah dilakukan terhadap variabel bangunan sekolah, sebagian besar sekolah di wilayah kerja puskesmas Mojopanggung Banyuwangi telah memiliki ruangan kelas yang bersih dari sampah ataupun debu, lingkungan yang bersih bisa tercipta karena upaya siswa dalam menjaga kebersihan lingkungan dengan mengadakan jadwal piket setiap harinya. Kursi dan meja tampak bersih dan diatur secara rapi, 
Banyuwangi

setiap kelas juga memiliki cukup cahaya dan udara segar. Didalam kelas masing-masing memiliki lampu yang dapat digunakan ketika ruangan gelap serta ventilasi sebagai jalan masuk dan keluarnya udara meskipun tidak dilengkapi kipas angin atau AC.

Ruangan guru sudah tampak bersih dan memiliki tempat sampah namun sebanyak 15 dari 22 sekolah (68\%) masih memiliki asbak di dalam ruangan, hal itu menandakan masih adanya warga sekolah yang merokok di sekolah. Padahal di dalam Peraturan Menteri Pendidikan dan Kebudayaan Republik Indonesia Nomor 64 tahun 2015 (Kementerian Pendidikan dan Kebudayaan Republik Indonesia, 2015) telah menerbitkan peraturan kawasan tanpa rokok di lingkungan sekolah. Isi peraturan tersebut melarang berbagai aktivitas yang berhubungan dengan rokok, seperti kegiatan memproduksi, menjual dan atau mempromosikan rokok. Kepala sekolah memiliki kewajiban untuk menegur atau memperingatkan atau mengambil tindakan seseorang yang merokok disekolah, baik itu guru, tenaga kependidikan, atau peserta didik.

\section{Gambaran Kebersihan Perorangan}

Berdasarkan hasil penelitian yang telah dilakukan terhadap variabel kebersihan perorangan, didapatkan hasil bahwa $86,4 \%$ dari total seluruh peserta didik di wilayah kerja puskesmas Mojopanggung sudah mampu menjaga kebersihan badan dan kuku. Masingmasing siswa di seluruh sekolah sudah seluruhnya (100\%) memiliki kondisi badan dan pakaian seragam yang bersih, namun ketika dilakukan pengamatan terhadap kebersihan kuku dan tangan siswa, masih ada murid di 6 sekolah (27\%) yang kukunya terlihat panjang dan hitam. Kebersihan tangan yang tepat diantaranya termasuk rajin membersihkan dan merapikan kuku yang mungkin mengandung kotoran dan kuman dan dapat menyebabkan penyebaran beberapa infeksi, seperti cacing kremi. Kuku jari harus dijaga tetap pendek, dan bagian bawahnya harus sering dibersihkan dengan sabun dan air. Karena kuku yang lebih panjang bisa menyimpan lebih banyak kotoran dan bakteri daripada kuku pendek, sehingga berpotensi berkontribusi terhadap penyebaran infeksi, untuk itu kebersihan kuku dan tangan harus dijaga (CDC, 2009). Berdasarkan hasil penelitian yang dilakukan oleh Amirawati terhadap siswa SD Inpres Cambaya Sungguminasa Gowa tahun 2012 didapatkan hasil bahwa sebanyak $45 \%$ dari jumlah seluruh siswa di sekolah terkena cacingan akibat kuku yang dibiarkan kotor dan panjang (Amri, 2012).

\section{Gambaran Lain-Lain}

Berdasarkan hasil penelitian yang telah dilakukan terhadap variabel lain-lain, didapatkan hasil bahwa sebagian besar sekolah menyediakan wastafel dan kotak P3K. selain itu, masing-masing sudah mendukung pelaksanaan kantin sekolah sehat. Seluruh sekolah yang menjadi sampel penelitian (100\%) telah menyediakan kotak P3K lengkap dengan isinya. Menurut Data Riset Kesehatan Dasar 2013, cidera paling banyak terjadi apabila diakumulasikan secara nasional di Indonesia dapat terjadi di jalan raya $(42,8$ persen), disusul oleh rumah (36,5 persen), dan sekolah (5,4 persen) untuk itu, mempersiapkan pertolongan pertama dibutuhkan untuk mengantisipasi dan pencegahan terhadap terjadinya risiko luka yang dapat menjadi masalah yang mengganggu berbagai kegiatan murid di sekolah.

Sebanyak 9 dari 22 sekolah $(40,1 \%)$ masih belum mempunyai westafel di tiap kelas. Sejalan dengan penelitian yang dilakukan Rosiy (2012) terhadap sarana pencucian tangan di Sekolah Dasar Kota Tembilahan Kabupaten Indragiri Hilir, hasil penelitian menunjukkan bahwa sebesar $34 \%$ sekolah dasar di Kota Tembilahan tidak memiliki sarana tempat pencucian tangan, sedangkan $17 \%$ diantaranya memiliki wastafel namun dalam keadaan yang buruk. Menurut Peraturan Menteri Kesehatan RI No. 1429 tahun 2006 minimal disediakan 1 tempat cuci tangan untuk 2 kelas, tempat cuci tangan harus dilengkapi air mengalir dan sabun (Kementerian Kesehatan Republik Indonesia, 2006). Menjaga kebersihan tangan melalui mencuci tangan adalah salah satu langkah terpenting yang bisa dilakukan untuk memutus rantai penularan penyakit dan menghindari penyebaran bakteri/kuman kepada orang lain. Banyak penyakit yang disebarkan akibat tidak mencuci tangan dengan bersih menggunakan sabun dan air mengalir. Jika air bersih tidak dapat diakses, seperti yang biasa terjadi di banyak belahan dunia, gunakan sabun dan air yang tersedia. Jika sabun dan air tidak tersedia, gunakan pembersih tangan berbasis alkohol 
Nur, et al. Inspeksi Kesehatan Lingkungan Sekolah Dasar Wilayah Kerja Puskesmas Mojopanggung Banyuwangi

yang mengandung setidaknya $60 \%$ alkohol untuk membersihkan tangan (CDC, 2009).

Sebanyak 16 kantin (73\%) di setiap sekolah dasar wilayah kerja puskesmas mojopanggung sudah dalam keadaan bersih tersedia tempat untuk mencuci tangan dan tempat sampah di setiap ruangan. Kantinkantin tersebut menjual makanan sehat yang sebagian besar dimasak sendiri oleh penjual. Sedangkan sisanya, yaitu sebanyak 6 kantin sekolah (27\%) masih belum memenuhi syarat. Hal tersebut dikarenakan kantin di 6 sekolah lainnya belum memiliki fasilitas sanitasi yang memadai dan masih menjual makanan tidak sehat. Keamanan pangan di sekolah karena menjadi sangat penting karena anak-anak lebih rentan terhadap penyakit, selain makanan yang disediakan harus sehat juga harus mementingkan keamanan pangan, karena siapapun bisa menjadi sakit karena penyakit yang berhubungan dengan bakteri atau virus yang mencemari makanan oleh karena itu kantin sekolah harus melakukan tindakan pencegahan ekstra.

\section{Gambaran Hasil Inspeksi Kesehatan Lingkungan Sekolah}

Berdasarkan hasil observasi dan penilaian yang telah dilakukan, sekolah A memiliki hasil tidak memenuhi syarat pada variabel bangunan / gedung, fasilitas sanitasi dan variabel lain-lain. Hal ini dikarenakan ketika inpeksi dilakukan, didapati guru sekolah sedang merokok di ruang guru. Peralatan piket seperti sapu, kemoceng dan cikrak diletakkan begitu saja dibagian belakang sehingga membuat kelas terlihat tidak rapi dan mengurangi estetika pemandangan. Peralatan kebersihan yang dibiarkan menumpuk juga dapat menjadi tempat perindukan nyamuk dan meningkatkan risiko terjadinya DBD.

Selain hal tersebut diatas, sekolah tidak memiliki tempat cuci tangan untuk siswa. Para siswa biasanya melakukan kegiatan cuci tangan di kamar mandi sekolah, pun didalam kamar mandi tidak disediakan sabun. Sehingga para siswa hanya membasuh tangan dengan air saja. Kantin sekolah juga masih menjual beberapa makanan yang mengandung pewarna, pemanis dan pengawet. Banyak dijumpai minuman sachet yang mengandung pemanis buatan dan berkarbonasi. Dalam pembuatan es sachet pun, penjual menggunakan es yang berasal dari air mentah untuk membuatnya.
JPH RECODE Oktober 2018; 2 (1) : 11-21 http://e-journal.unair.ac.id/JPHRECODE

Penjual sudah menjual makanan sehat yang diokah secara mandiri seperti gorengan, namun penjual tidak menutupi makanan yang disajikan, sehingga lalat dapat dengan mudah menempel pada tiap makanan yang disediakan. Selain itu, penggunaan saos masih dilakukan. Sambal dan saos yang tidak habis masih disimpan di botol yang sama dan tidak akan diganti sebelum isinya habis.

Berdasarkan hasil observasi dan penilaian yang telah dilakukan di sekolah $G$ dan sekolah $\mathrm{H}$ variabel yang tidak memenuhi syarat adalah fasilitas sanitasi. Di kedua SD tersebut terdapat 2 kamar mandi siswa yang masih terlihat kotor karena adanya sampah yang tidak dibuang di tempat sampah (tidak tersedianya tempat sampah di kamar mandi), selain itu juga tercium bau yang kurang sedap bahkan ketika masih diluar ruangan. Hal ini terjadi karena kebiasaan siswa yang kurang banyak menyiram air kedalam jamban/toilet. Meskipun sekolah dasar ini sudah memiliki jamban yang memenuhi syarat, namun pembuangan air limbah kamar mandi langsung dialirkan ke sungai.

Berdasarkan hasil observasi dan penilaian terhadap sekolah Q, secara keseluruhan sekolah sudah baik, namun ketika kunjungan terlihat banyaknya sampah yang masih menumpuk di tempat sampah dan belum dibuang selama 3 hari. Dalam pengelolaan sampah, sekolah Q hanya membakarnya, biasanya sampah dibakar di area kebun sekolah dan menunggu sampah terkumpul dalam jumlah banyak. Hal ini terpaksa dilakukan oleh pihak sekolah karena tidak adanya pasukan kuning yang bersedia mengambil sampah ke wilayah mereka yang tergolong jauh dari TPA. Selain itu, ketika dilakukan pengamatan kepada sejumlah siswa (kurang lebih 15 siswa) yang saat itu sedang beristirahat, kuku siswa terlihat panjang dan hitam. Selain itu, di Sekolah Q terdapat 3 kamar mandi sekolah namun hanya 1 yang bisa digukan karena rusak.

\section{KESIMPULAN}

Berdasarkan hasil penelitian yang telah dilakukan di wilayah kerja Puskesmas Mojopanggung menunjukkan bahwa terdapat 4 $(18,18 \%)$ sekolah yang kurang memenuhi syarat dan $18 \quad(81,81 \%)$ sekolah yang memenuhi syarat kesehatan berdasarkan hasil penilaian seluruh variabel di masing-masing 
Nur, et al. Inspeksi Kesehatan Lingkungan Sekolah Dasar Wilayah Kerja Puskesmas Mojopanggung Banyuwangi

sekolah sesuai form Dinas Kesehatan Provinsi Jawa Timur.

Berdasarkan hasil penilaian kesehatan lingkungan di seluruh sekolah per variabel, didapatkan hasil bahwa seluruh variabel telah memenuhi syarat. Seluruh sekolah (100\%) sudah memiliki lingkungan sekolah yang memenuhi syarat, terdapat 20 sekolah $(90,9 \%)$ memiliki fasilitas sekolah yang memadai dan 21 sekolah $(95,4 \%)$ memiliki bangunan sekolah yang layak. Terdapat peserta didik di 19 sekolah $(86,4 \%)$ memiliki kebersihan badan dan kuku yang baik dan sebanyak 18 sekolah $(81,8 \%)$ memiliki wastafel, P3K dan Kantin Sekolah yang memadai.

\section{SARAN}

Saran yang dapat diberikan bagi peneliti selanjutnya yaitu ruang lingkup $p$ enelitian lebih diperluas lagi agar dapat diketahui kondisi sanitasi lingkungan sekolah di wilayah lain yang terdapat di Kabupaten Banyuwangi. Karena penelitian yang dilakukan oleh penulis hanya mencakup satu wilayah kerja puskesmas saja.

Saran untuk sekolah yang sudah memiliki lingkungan sekolah yang memenuhi syarat ataupun belum memenuhi syarat, hendaknya sekolah sebagai pihak internal selalu melakukan upaya promosi kesehatan lingkungan sekolah dan PHBS secara rutin. Didalam peraturan menteri kesehatan nomer 1429 tahun 2006 sudah dijelaskan bahwa upaya promosi kesehatan bisa dilakukan oleh pihak selain petugas puskesmas (Kementerian Kesehatan Republik Indonesia, 2006). Upaya KIE ini dilakukan guna meningkatkan pengetahuan siswa dan menumbuhkan perilaku yang hygine. Selain itu, guru dan kepala sekolah juga harus menerapkan dan mencontohkan dengan baik juga mengadvokasi pemerintah setempat untuk menyediakan fasilitas atau sarana sanitasi yang masih belum terpenuhi agar siswa mampu mempraktikkan ilmu yang sudah diperoleh setelah sosialisasi dilakukan. Tanpa adanya stimulus dari sarana sanitasi yang baik, maka perilaku siswa akan sulit dibentuk, dengan adanya perbaikan sarana sanitasi maka akan berpengaruh pada peningkatan kesehatan siswa karena faktor lingkungan (sanitasi).

\section{DAFTAR PUSTAKA}

Amri, S. A. 2012. Gambaran Hygiene
JPH RECODE Oktober 2018; 2 (1) : 11-21 http://e-journal.unair.ac.id/JPHRECODE

Perorangan, Sanitasi Lingkungan Sekolah dan Infeksi Kecacingan Pada Murid SD Inpres Cambaya Sungguminasa Gowa. (Skripsi, UIN Alauddin Makassar, Makassar). Diakses dari: http://repositori.uinalauddin.ac.id/1992/1/SITI AMIRAWATI AMIR.pdf.

Arisandi, D., Junaid dan Ismail, cece suriani. 2015. Gambaran Sanitasi Sekolah Dasar Kecamatan PoliPolia Dan Kecamatan Ladongi Di Kolaka Timur Tahun 2015, JIMKesmas (Jurnal Ilmiah Mahasiswa Kesehatan Masyarakat), 49(23-6), pp. 1-11. Diakses dari: http://ojs.uho.ac.id/index.php/JIMK ESMAS/article/view/1210/857.

Burnet Institute. 2015. Menstrual Hygiene Management in Indonesia "Understanding practices, determinants and impacts among adolescent school girls" Final Repor.

CDC. 2009. Handwashing and Nail Hygine. USA: Department of Health \& Human Services. Diakses dari: https://www.cdc.gov/healthywater/h ygiene/hand/nail_hygiene.html.

Endang, W. 2014. Pencemaran di Perairan Sungai. Diakses dari: http://bio.unsoed.ac.id/sites/default/f iles/Pencemaran di Perairan Sungai.pdf.

Freeman, MC, Stocks, ME, Cumming O, Jeandron A, Higgins JP, W. J. and Pruss-Ustun A, Bonjour, S, Hunter PR, Fewtrell L, C. V. 2014. Hygiene and helath: systematic review of handwashing practises worlwide and update of helath effets, Trop Med Int Health, 19(8), pp. 906-916.

Freeman, R. B. 2006. People Flows in Globalization, Journal of Economic Perspectives, 20(2), pp. 145-170.

Kementerian Kesehatan Republik Indonesia. 1990. Peraturan Menteri Kesehatan Nomor : 416/MEN.KES/PER/IX/1990

Tentang Syarat-syarat Dan Pengawasan Kualitas Air.

Kementerian Kesehatan Republik Indonesia. 2006. Keputusan Menteri Kesehatan Republik Indonesia No. 1429 Tahun 2006 Tentang Pedoman 
Nur, et al. Inspeksi Kesehatan Lingkungan Sekolah Dasar Wilayah Kerja Puskesmas Mojopanggung Banyuwangi
Penyelenggaraan
Kesehatan Lingkungan Sek

Kementerian Pendidikan dan Kebudayaan

Republik Indonesia. 2015. Peraturan Menteri Pendidikan Dan Kebudayaan Republik Indonesia Nomor 64 Tahun 2015 Tentang Kawasan Tanpa Rokok Di Lingkungan Sekolah.

Mukono, H. J. 2006. Prinsip Dasar Kesehatan Lingkungan, Edisi Kedua, Airlangga University Press. doi: 28/9/2289 [pii].

Notoatmojo, S. 2010. Metodologi Penelitian Kesehatan. Jakarta: Rineka Cipta.

Pusat Data dan Statistik Pendidikan dan Kebudayaan. 2017. Profil Sanitasi Sekolah Tahun 2017. Dikases dari: http://www.ampl.or.id/pdf/unicef/Pr ofil_Sanitasi_Sekolah_Tahun_2017. pdf.

Rosiy, A. 2012. Studi Deskriptif Sarana Sanitasi Dasar Pada Sekolah Dasar di Kota Tembilah Kabupaten Indragiri Hilir Provinsi Riau, Skripsi, Universitas Indonesia, Depok. Diakses dari: http://lib.ui.ac.id/file?file=pdf/abstra k-20354479.pdf.

Supriyanto, B. 2000. Pengelolaan Air Limbah Yang Berwawasan Lingkungan Suatu Strategi Dan Langkah Penangannya, Jurnal Teknologi Lingkungan, 1(1), pp. 1726. Diakses dari: http://www.kelair.bppt.go.id/Jtl/200 0/vol1-1/03airlim.pdf.

Tambuwun, F. et al. 2015. Hubungan sanitasi lingkungan dengan kejadian diare pada anak usia sekolah di wilayah kerja puskesmas bahu manado, Jurnal Keperawatan, 3(2), pp. 1-8. Diakses dari: https://ejournal.unsrat.ac.id/index.ph $\mathrm{p} / \mathrm{jkp} / \mathrm{article} / \mathrm{view} / 8035 / 7596$.

UNESCO. 2010. Out-ofSchool Adolescents, Montreal, Canada; UNESCO Institute for Statistic.

UNICEF Indonesia. 2012. Ringkasan Kajian Air Bersih, Sanitasi dan Kebersihan. Diakses dari: https://www.unicef.org/indonesia/id/ A8_-

_B_Ringkasan_Kajian_Air_Bersih.
JPH RECODE Oktober 2018; 2 (1) : 11-21 http://e-journal.unair.ac.id/JPHRECODE

pdf.

UU RI. 2009. UU RI No 36 Tentang Kesehatan, UU RI No 362009. 